This is a self-archived - parallel published version of this article in the publication archive of the University of Vaasa. It might differ from the original.

\title{
Examining the effects of interorganizational learning on performance : a meta-analysis
}

Author(s): Rajala, Anni

Title: Examining the effects of interorganizational learning on performance : a meta-analysis

Year: $\quad 2018$

Version: Accepted manuscript

Copyright (C)2018 Emerald. Creative Commons AttributionNonCommercial 4.0 International (CC BY-NC 4.0) license, https://creativecommons.org/licenses/by-nc/4.o/

Please cite the original version:

Rajala, Anni (2018). Examining the effects of interorganizational learning on performance : a meta-analysis. Journal of business and industrial marketing, 33(4), 574-584. https://doi.org/10.1108/JBIM-08-2017-0205 
Rajala, Anni (2018). Examining the effects of interorganizational learning on performance : a metaanalysis. Journal of business and industrial marketing, 33(4), 574-584.

\title{
EXAMINING THE EFFECTS OF INTERORGANIZATIONAL LEARNING ON PERFORMANCE:
}

\section{A MetA-ANALYSIS}

\section{Anni Rajala}

\begin{abstract}
Purpose: Relationship learning is viewed as an important factor in enhancing competitiveness and an important determinant of profitability in relationships. Prior studies have acknowledged the positive effects of interorganizational learning on performance, but the performance measures applied have varied. The purpose of the current paper is to examine the relationship between interorganizational learning and different types of performance. The paper also goes beyond direct effects by investigating the moderating effects of different research designs.

Design/methodology/approach: This paper applies a meta-analytic approach to systematically analyze 21 independent studies $(\mathrm{N}=4618)$ to reveal the relationship between interorganizational learning and performance.

Findings: The findings indicate that interorganizational learning is an important predictor of performance, and that the effects of interorganizational learning on performance differ in magnitude under different research conditions.

Research limitations/implications: The paper focuses on interorganizational learning, and during the data collection some related topics were excluded from the data search in order to retain the focus on learning.
\end{abstract}

Practical implications: The study evinces the breadth of the field of interorganizational learning and how different research designs affect research results. Moreover, this meta-analysis indicates the need for greater clarity when defining the concepts used in studies, and for definitions of the concepts applied in the field of interorganizational learning to be unified.

Originality/value: This study is the first to meta-analytically synthesize literature on interorganizational learning. It also illuminates new perspectives for future studies within this field.

Keywords: Interorganizational learning, relationship learning, performance, meta-analysis

Paper type: Research paper 
Rajala, Anni (2018). Examining the effects of interorganizational learning on performance : a metaanalysis. Journal of business and industrial marketing, 33(4), 574-584.

\section{Introduction}

Interorganizational knowledge sharing and learning are one of the main avenues for improving the performance of the supply chain in today's business environment (Hernández-Espallardo, RodríguezOrejuela, \& Sánchez-Pérez, 2010). Moreover, it has been argued that competition is no longer among companies but among supply chains (Hernández-Espallardo et al., 2010; Wowak, Craighead, Ketchen, \& Hult, 2013). We are also witnessing growing interest in the extent to which supply chains affect performance. Through interactions with external partners, and learning from them, companies access new knowledge, resources, and techniques (Fang, Fang, Chou, Yang, \& Tsai, 2011). Furthermore, interorganizational learning (IOL) is seen as an important domain in the creation of competitive advantage (e.g., Ling-yee, 2006; Liu, 2012), and accordingly scholars have recently turned their attention to the relationship between learning and performance (e.g., Gao, Li, Cheng, \& Feng, 2017; Huang \& Li, 2017; Jean, Chiou, \& Sinkovics, 2016).

Various conceptualizations of IOL can be observed in the extant literature. In some cases, IOL has been defined as a joint activity through which parties share information, interpret it, and integrate it into relationship-specific memory (e.g., Selnes \& Sallis, 2003), while others indicate that IOL is an interactive process resulting in knowledge exchange (e.g., Huang \& Chu, 2010). Although researchers agree that IOL requires information sharing, there has been no consistent agreement regarding which activities contribute to forming IOL. Thus, there is a lack of consensus among researchers as to what constitutes IOL. However, regardless of the variety of conceptualizations, the positive effects of IOL on performance are widely acknowledged (e.g., Chang \& Gotcher, 2007; Chen, Lin, \& Chang, 2009; Selnes \& Sallis, 2003). The positive effects of IOL on performance relate to market performance (e.g., Chen et al., 2009), relationship performance (e.g., Selnes \& Sallis, 2003), innovation 
Rajala, Anni (2018). Examining the effects of interorganizational learning on performance : a metaanalysis. Journal of business and industrial marketing, 33(4), 574-584.

performance (e.g., Leal-Rodríguez, Roldán, Ariza-Montes, \& Leal-Millán, 2014), and operational performance (e.g., Cheung, Myers, \& Mentzer, 2010).

Even though there appears to be agreement among researchers that IOL can enhance performance, an important question remains concerning the magnitude of IOL on improving performance. Some studies report strong IOL-performance relationships (e.g., Cheung, Myers, \& Mentzer, 2011; LealRodríguez et al., 2014; Selnes \& Sallis, 2003), while other studies find it more modest (e.g., Johnson \& Sohi, 2003; Sobrero \& Roberts, 2001; Wang \& Hsu, 2014). Consequently, there are different findings among studies concerning the effects of IOL on performance. Moreover, a second unanswered question concerns under what conditions the IOL-performance relationship have different magnitude, and more specifically, how do different research designs affect the IOLperformance relationship. Understanding the effect of a research design on the IOL-performance link is important because it has implications for future research. For example, if the relationship is stronger under a certain condition, researchers might want to explain the difference in strength under other conditions and address how it might be overcome.

The paper investigates the overall relationship between IOL and performance in supply chain context, and how various research designs affect the connection. To investigate these issues, the present study examines 21 independent studies (including 26 samples, $\mathrm{N}=4618$ ) systematically through a metaanalytic procedure. Meta-analysis is a technique that empirically combines previous findings to estimate the size of a relationship between variables. Meta-analysis controls for statistical artifacts (i.e., sampling and measurement error) and therefore offers more accurate estimates than other types of assessments (Schmidt \& Hunter, 2015). This paper contributes to the IOL literature by examining the IOL-performance link and how it differs in magnitude across different research settings. The main objective of the paper is to examine the efficiency of various forms of IOL on performance, and 
Rajala, Anni (2018). Examining the effects of interorganizational learning on performance : a metaanalysis. Journal of business and industrial marketing, 33(4), 574-584.

whether the impact of IOL on different types of performance varies. Further, the aim of the paper is not merely to examine the IOL-performance relationship but also to consider which research conditions might alter that relationship. Moreover, the paper contributes to the IOL literature by comparing different perspectives on IOL applied in prior research, and by attempting to unify the different views.

The paper is organized as follows. It begins by setting out the theoretical background and outlining the development of its hypotheses. Next, the method is described, and then results are presented. Finally, the main findings are discussed and implications for future research and for management are proposed.

\section{Theoretical background and hypotheses}

Prior research has viewed interorganizational learning (IOL) from several different perspectives. One of the most cited perspectives on interorganizational learning is that of relationship learning proposed by Selnes and Sallis (2003) (see e.g., Cheung, Myers, \& Mentzer, 2011; Jean, Kim, \& Sinkovics, 2012; Ling-yee, 2006). Relationship learning is defined as "a joint activity between a supplier and a customer in which the two parties share information, which is then jointly interpreted and integrated into shared relationship-domain-specific memory that changes the range or likelihood of potential relationship-domain-specific behavior" (Selnes \& Sallis, 2003, p. 86). Relationship learning includes three sub-processes: information sharing, joint sense-making, and knowledge integration (Selnes \& Sallis, 2003). A starting point of interorganizational learning is infomation sharing. In order to coordinate collaboration and achieve operational efficiency, it is necessary for parties to a relationship to share knowledge (Selnes \& Sallis, 2003). Each organization has a different ability to acquire information and thus joint sense-making varies across organizations. Finally, acquired knowledge is 
Rajala, Anni (2018). Examining the effects of interorganizational learning on performance : a metaanalysis. Journal of business and industrial marketing, 33(4), 574-584.

integrated into relationship-specific memory, which encompasses organizational beliefs, behavioral routines, and physical artifacts (Selnes \& Sallis, 2003). Knowledge integration is essential to bring the new knowledge into use and deliver the expected performance benefits (Kohtamäki \& Partanen, 2016).

Moreover, IOL has also been conceptualized through absorptive capacity, which is "a firm's ability to recognize the value of new, external knowledge, assimilate it, and apply it to commercial ends" (Lane \& Lubatkin, 1998, p. 462). Thus, IOL occurs when a partner acquires knowledge, assimilates it, and exploits it in its operations (Schildt, Keil, \& Maula, 2012). Furthermore, Lane and Lubatkin (1998) argue that interactive learning is necessary to add unique value to a firm's own capabilities. Interactive learning occurs between two firms, and the acquired knowledge is unique and hardly imitable. Moreover, acquiring that complex knowledge demands intensive interactions (Lane \& Lubatkin, 1998). However, there are also views arguing that absorptive capacity is a company's internal capability that is needed to enhance performance in a similar manner to relationship learning (Chen et al., 2009). In addition, absorptive capacity is seen as an indicator of a firm's ability to learn and build anew on prior knowledge, and accordingly different organizations will have different abilities to assimilate and apply new knowledge (Liu, 2012). Thus, absorptive capacity is also seen as an antecedent of relationship learning (Liu, 2012).

Moreover, the interactive learning perspective views acquisition of new knowledge as occurring through interaction between members from different organizations, which results in knowledge exchange and knowledge transfer between organizations (e.g., Hernández-Espallardo et al., 2010; Huang \& Chu, 2010; Knight, 2002). Thus, this knowledge transfer between organizations is seen as an intensive personal contact and interaction (Huang \& Chu, 2010). Moreover, scholars have adopted a communicative and interactive perspective when investigating interorganizational learning (e.g., 
Rajala, Anni (2018). Examining the effects of interorganizational learning on performance : a metaanalysis. Journal of business and industrial marketing, 33(4), 574-584.

Huang \& $\mathrm{Chu}, 2010)$. Further, the interaction school suggests that firms in a relationship simultaneously affect, and are affected by, each other in many ways (Håkansson \& Shenota, 1995). There are also studies (e.g., Yang, 2012) that view IOL as knowledge acquisition across organizational boundaries. Moreover, Knight (2002) state that IOL literature has a strong focus on what each firm can learn from interaction with other firms, and further that such interaction might lead to joint learning; however, the focus is typically on how each firm can derive private benefits.

Despite the different perspectives on IOL, there are similarities. Common to all the perspectives on IOL is that each emphasizes the importance of interaction. Moreover, all these views acknowledge that information and/or knowledge sharing occurs in continuous interaction. In addition, the perspectives share the belief that IOL begins with information/knowledge sharing in an interorganizational relationship, then the acquired knowledge is interpreted, and finally it is applied in practice. The main difference between these views is if the process of IOL occurs at a relationship level or at an organizational level. The relationship learning perspective states that learning occurs at the relationship level. Once information has been shared, a joint sense-making process begins, and that leads to knowledge integration. In contrast, the absorptive capacity/interactive learning view holds that knowledge is shared and transferred at the relationship level, but assimilation or interpretation of the acquired knowledge occurs within organizations, which also means that applying knowledge in practice also occurs within organizations. Moreover, Huang and Chu (2010) state that interactive learning can be viewed as a catalyst for internalized learning. In sum, relationship learning is joint learning, whereas interactive learning is more about knowledge acquisition. However, Lane and Lubatkin (1998) also argue that factors that influence one-way learning also affect two-way learning. 
Rajala, Anni (2018). Examining the effects of interorganizational learning on performance : a metaanalysis. Journal of business and industrial marketing, 33(4), 574-584.

Prior studies have examined the effects of interorganizational learning from different viewpoints. Relationship learning has been viewed as an important factor in enhancing competitiveness and an important determinant of profitability in relationships (Chen et al., 2009; Ling-yee, 2006; Yang \& Lai, 2012). A widely used performance measure in IOL studies is relationship performance (e.g., Johnson \& Sohi, 2003; Ling-yee, 2006; Selnes \& Sallis, 2003), which addresses the extent to which the parties to the relationship are satisfied with the effectiveness (i.e., doing the right things) and the efficiency (i.e., doing things in the right way) of the relationship (Jean \& Sinkovics, 2010). Further, prior studies have confirmed the positive relationship between IOL and operational performance (e.g., Cheung, Myers, \& Mentzer, 2010; Hernández-Espallardo et al., 2010). Operational performance includes measures such as cost, quality, speed, development capability, and delivery performance. Moreover, the positive effect of IOL on market performance (i.e., market share, sales growth, profitability) has been addressed in previous studies (e.g., Chang \& Gotcher, 2010; Jean, Sinkovics, \& Kim, 2010). Studies have also found a positive innovation performance effect (i.e., product innovation, process innovation, overall innovativeness) resulting from IOL (e.g., Chen et al., 2009; Fang et al., 2011).

Based on the number of publications that have provided empirical support for the IOL-performance link (e.g., Chen et al., 2009; Cheung et al., 2010; Selnes \& Sallis, 2003), it is hypothesized a positive performance effect resulting from interorganizational learning.

Hypothesis 1: Interorganizational learning is positively related to performance.

The current research considers the effect of several potential moderators in its attempt to examine the relationship between IOL and performance closely. First, to structure the analysis of the effect of 
Rajala, Anni (2018). Examining the effects of interorganizational learning on performance : a metaanalysis. Journal of business and industrial marketing, 33(4), 574-584.

interorganizational learning on performance, the type of performance is classified into four dimensions: market performance, relationship performance, innovation performance, and operational performance. Prior studies have confirmed a positive relationship between IOL and all of these performance types. Interorganizational learning requires interaction and information sharing in relationships (e.g., Huang \& Chu, 2010; Selnes \& Sallis, 2003), and thus as two organizations engage in mutual learning, they become more likely to understand each other, which results in enhanced relationship performance (Selnes \& Sallis, 2003). Although this acquired learning can result in innovation or operational performance, it can be assumed that IOL has a stronger relationship with relationship performance than with other types of performance. Moreover, market performance is an outcome of a combination of multiple variables, and IOL is one such (e.g., Chang \& Gotcher, 2010; Fang et al., 2011). However, it can be assumed that the effects of IOL are weaker on market performance than other types of performance, because it takes time to turn IOL into something useful in practice, and thus the profit from learning is subject to a time lag. Accordingly, it is hypothesized:

Hypothesis 2A: Research designs studying the link between IOL and relationship performance will report a stronger IOL-performance connection than research designs relying on other performance types.

Hypothesis 2B: Research designs studying the link between IOL and market performance will report a weaker IOL-performance relationship than research designs relying on other performance types.

Moreover, IOL has been viewed through different theoretical lenses. Studies building on relationship learning theory have adapted the view and measures from the work of Selnes and Sallis (2003), which is quite established in the context of studying IOL in a network setting. Other theoretical backgrounds suggested for IOL have not established ways to measure and conceptualize IOL to the same extent. 
Rajala, Anni (2018). Examining the effects of interorganizational learning on performance : a metaanalysis. Journal of business and industrial marketing, 33(4), 574-584.

Accordingly, it can be predicted that studies adopting the relationship learning perspective will report a stronger IOL-performance link than studies built on other theoretical foundations. This is because the relationship learning measure is established and has been found to be suitable for measuring IOL, while other types of IOL measures are diverse and focus on different aspects of IOL.

Hypothesis 3: Studies relying on the relationship learning view will have a stronger positive IOL-performance relationship than studies relying on another theoretical background.

\subsection{Interorganizational learning and performance: methodological moderators}

These moderators relate to how the original studies were designed. It is assumed that a potential moderator between IOL and performance is global breadth. Studies using data from single countries may report a stronger connection between IOL and performance, because it has been argued that "by focusing on a single country, researchers can theorize and design their research to more fully capture the nuances of the country" (Wowak et al., 2013, p. 847). Moreover, samples from multiple countries may be diverse in terms of cultural impact, governmental regulations, and overall development, and these issues may affect the extent to which companies share information (Liu, 2012; Wowak et al., 2013). Thus, it is hypothesized:

Hypothesis 4: IOL-performance connection is stronger in research designs using samples from single countries than in studies relying on samples from multiple countries.

Similar to the reasoning identifying the potential moderator of global breadth, industry diversity may have an impact on the IOL-performance relationship. Articles that use samples from multiple industries may not fully capture the effect of IOL on performance, because it may differ across industries. Studies focusing on a single industry may reflect the effect of IOL on performance more 
Rajala, Anni (2018). Examining the effects of interorganizational learning on performance : a metaanalysis. Journal of business and industrial marketing, 33(4), 574-584.

accurately, because those studies are designed and implemented according to contextual dimensions of the industry. Hence, it is hypothesized:

Hypothesis 5: IOL-performance connection is stronger in research designs using samples from single industry than research designs relying on samples from several industries.

Finally, IOL studies assert that interaction and information sharing are necessary antecedents of IOL (e.g., Chen et al., 2009). Prior IOL studies have argued that inter-firm learning moves from buyer to supplier (see e.g., Hammervoll, 2012; Rebolledo \& Nollet, 2011). This is logical because suppliers aim to attract customers and adapt their products and services to customer needs. Suppliers are also willing to invest time and resources to obtain knowledge from their customers that can move them closer to their markets (Cheung et al., 2011). Some sub-dimensions of IOL might also demand time and resources from the buyers, while simultaneously enhancing the relationship value for suppliers (Cheung et al., 2011). It is therefore logical that the IOL-performance connection will be reported to be stronger in studies using samples drawn only from suppliers. Moreover, correlations between IOL and performance seem to be stronger in supplier studies than in buyer studies (see e.g., Cheung et al., 2011) suggesting that the relationship might be reported as stronger in studies using supplier samples. Thus, it is hypothesized:

Hypothesis 6: IOL-performance connection is stronger in research designs focusing on suppliers than in studies focusing on customers, or for both customers and suppliers. 
Rajala, Anni (2018). Examining the effects of interorganizational learning on performance : a metaanalysis. Journal of business and industrial marketing, 33(4), 574-584.

Meta-analysis incorporates variations in independent and dependent variables depending on the hypothesis and the purpose of the original study, designs, measures, and samples. This is known as the "apples and oranges" problem (Cheung \& Vijayakumar, 2016; Schmidt \& Hunter, 2015), and it is a common criticism of meta-analysis. However, Schmidt and Hunter (2015) argue that synthesizing findings from different settings is actually a strength of meta-analysis.

The present study applies meta-analytical techniques to previously conducted research to examine the relationship between interorganizational learning and performance. Furthermore, an analysis is conducted to determine the existence of the hypothesized moderators above.

\subsection{Literature search and study selection}

A systematic literature review was conducted. The target was to identify scientific articles from the Scopus database and EBSCO Business Source using the key words: "interorganizational learning", “inter-organizational learning", "relationship learning", "relational learning", and "network learning". Conference abstracts, working papers, dissertations/theses were excluded from the results and a total of 413 articles were subsequently found. The abstracts of those articles were reviewed manually, and a total of 94 articles identified as concerning the topic in question. It was set criteria for the inclusion and exclusion of studies in line with the methodological approach, the scope of the research topic, and the availability of the data. These 94 articles were read and 70 of them found to discuss the type of interorganizational learning that is central to this paper. Among the 70,19 were qualitative studies and nine were conceptual, and therefore those 28 were excluded from further analysis. Among the remaining 42 quantitative articles, learning was treated as an antecedent in 11 articles, as a mediator in 15 articles, as a moderator in four articles, and as an outcome 12 articles. In 21 of these 42 articles the authors reported a correlation between interorganizational learning and 
Rajala, Anni (2018). Examining the effects of interorganizational learning on performance : a metaanalysis. Journal of business and industrial marketing, 33(4), 574-584.

performance and accordingly, these studies were included in the meta-analysis. Ultimately, the literature search and screening process identified 21 independent studies, including 26 samples and a total sample size of 4618 buying and supplying firms. This sample size is in line with other studies using meta-analysis. For example, Nair (2006) conducts a meta-analysis on 23 articles, and MacKelprang and Nair (2010) on 25 articles.

After the articles were collated, the unit of analysis used was the study itself, not the individual effect. Studies were coded accordingly, however, two studies reported on buyer and supplier studies separately and these were treated as separate studies in the next stage of the analysis. If a study report multiple effects, the correlations were averaged and a single estimate was used (Schmidt \& Hunter, 2015). Further, studies were coded in accordance with the hypotheses. For H2, articles were coded in accordance of the studied performance type, more specifically, articles were grouped into one of the four performance categories: market performance (i.e., market share, sales growth, or profitability), relationship performance (i.e., relationship efficiency, relationship effectiveness, or commitment), innovation performance (i.e., product innovation, process innovation, or overall innovativeness), and operational performance (i.e., quality, speed, development capability, or cost); for H4, articles were coded in accordance with their global diversity (single country/multiple countries); for H5, in accordance with industry diversity (single industry/multiple industry); and for H6, in accordance with the source of the data (customer/supplier/both). The number of studies in these different groups varied depending on whether the particular information was reported in an original article and could therefore be included in the groups. Table 1 presents the papers included in the meta-analysis.

Please insert Table 1 about here 


\subsection{Meta-analytic procedures}

The meta-analysis was conducted by following the Hunter-Schmidt method because it corrects for artifacts that attenuate correlations. The method dictates that if a study reports correlations between several sub-dimensions of learning and performance, or uses several performance measures, these values should be averaged to obtain a single estimate for each study (Crook, Ketchen JR, Combs, \& Todd, 2008). However, if a study reports correlations separately from a buyer and a supplier study, these should be treated as two separate studies (Salas et al., 2008).

Effect size estimates were calculated as the mean of the sample size weighted correlations: $\bar{r}=\sum\left[n_{i}\right.$ $\left.r_{i}\right] / \sum n_{i}$, where $n_{i}$ is the sample size and $r_{i}$ is the effect reported in the $i$ th study (Schmidt \& Hunter, 2015). This particular estimate provides greater precision than the estimates obtained from any study because positive and negative sampling errors cancel each other out (Crook et al., 2008; Hunter \& Schmidt, 1994; Schmidt \& Hunter, 2015). After sampling errors, measurement error has the second largest impact on findings. However, most IOL studies do not report reliability coefficients for every measure, and it is therefore impossible to correct each study individually for measurement error. Thus, the mean of available reliabilities was used to correct $\bar{r}$ to $\bar{r}_{\mathrm{c}}$ by using the formula $\bar{r}_{\mathrm{c}}=\bar{r} /\left(\sqrt{ } \bar{r}_{\mathrm{xx}} \sqrt{ } \bar{r}_{\mathrm{yy}}\right)$ (Wowak et al., 2013).

A chi-square test of homogeneity was conducted to test for the presence of heterogeneity in the observed correlations (Schmidt \& Hunter, 2015), moreover, an important question in meta-analysis is if a large amount of unexplained variance remains after accounting for study artifacts. This can be tested by calculating $X^{2}{ }_{\mathrm{K}-1}=\left(\mathrm{T} /\left(1-\bar{r}^{2}\right)^{2}\right) \mathrm{s}_{\mathrm{r}}^{2}$, where $\mathrm{K}$ is the number of effects, $\mathrm{T}$ is the total sample size, and $\mathrm{s}^{2}{ }_{\mathrm{r}}^{-}$is the observed variance of $\bar{r}$. A significant chi-square value indicates the presence of moderators in the samples (Combs \& Ketchen, 2003; Tong \& Crosno, 2015). Confidence intervals 
Rajala, Anni (2018). Examining the effects of interorganizational learning on performance : a metaanalysis. Journal of business and industrial marketing, 33(4), 574-584.

were calculated around each $\bar{r}$ using formulas provided by Schmidt and Hunter (2015). Confidence intervals were used to facilitate the hypothesis testing (e.g., Whitener, 1990). Relationships without a zero in the confidence intervals are considered to be significant (Lewin \& Donthu, 2005). Further, overlapping confidence intervals indicate that these studies have the same population or category (Schmidt, 1996). Moreover, according to Schmidt and Hunter (2015) a moderator variable manifests itself in two ways: (1) varying average correlations among subsets, and (2) the corrected variance will average lower results in the subsets than for the whole data.

Finally, a funnel plot was used to investigate whether publication bias might impact the results. If the publication bias is not present, a funnel plot is symmetric around the mean effect (McDaniel, Rothstein, \& Whetzel, 2006; Schmidt \& Hunter, 2015). The funnel plot is symmetric in the current case, except that two samples are located at the middle, right-hand side of the funnel. However, these samples could not be removed because they derive from the original work of Selnes and Sallis (2003), which is one of the most cited papers on relationship learning. Consequently, the file drawer test was conducted, which means that Rosenthal's fail-safe N was calculated. The fail-safe N computes how many missing effect sizes would have to be retrieved and incorporated in the analysis to affect the results. There are no clear guidelines for the fail-safe N, but a general guideline used states fail-safe an $\mathrm{N}$ equal to or greater than five times the number of studies in the original meta-analysis, plus 10 studies $(5 \mathrm{~K}+10)$ should indicate that the meta-analytic results are robust in the face of publication bias (McDaniel et al., 2006). In the current meta-analysis, the fail-safe $\mathrm{N}$ is 134.82 , which is marginally below the guideline threshold of 140 (calculated according to $5 \mathrm{~K}+10$ ). Thus, it was concluded that the risk of publication bias is a tolerable one.

\section{Results}


Rajala, Anni (2018). Examining the effects of interorganizational learning on performance : a metaanalysis. Journal of business and industrial marketing, 33(4), 574-584.

H1 suggesting that IOL has a positive relationship with performance was supported. The estimate of the effect size is $\bar{r}=0.46$. This estimate rises after correcting for measurement to $\bar{r}_{\mathrm{c}}=0.53$. Moreover, the $X^{2}$ statistic is significant $\left(X^{2}=212.19, \mathrm{p}<0.001\right)$, which indicates that moderators probably exist. Because of the results of the funnel plot, H1 was also tested without the samples from Selnes and Sallis (2003), because of their relative weight in the analysis. These results are in line with earlier ones and show that IOL has a positive relationship with performance $\left(\bar{r}=0.42 ; \bar{r}_{\mathrm{c}}=0.48\right)$, however, excluding the samples from the work of Selnes and Sallis (2003) does weaken the relationship somewhat. Further, the confidence intervals in single studies did not overlap with each other, which indicates that moderator variables exist.

$\mathrm{H} 2$ suggests that the IOL-performance is moderated by the type of measured performance. More specifically, H2a suggest that IOL-performance connection is stronger in studies using relationship performance than other types of performance, and the analysis provided partial support for this hypothesis. The confidence intervals of studies using relationship performance overlap with each other, which indicates that H2a is supported (see e.g., Schmidt, 1996). H2b predicts that studies using market performance will report a weaker relationship between IOL and performance and the analysis partially supports this prediction. Again, the confidence intervals of market performance strongly overlap, indicating that market performance studies can be treated as the same category and the result can be evaluated as significant. The effects of different types of measured performance are market performance $\bar{r}=0.36\left(\bar{r}_{\mathrm{c}}=0.43\right)$, relationship performance $\bar{r}=0.50\left(\bar{r}_{\mathrm{c}}=0.57\right)$, innovation performance $\bar{r}=0.40\left(\bar{r}_{\mathrm{c}}=0.44\right)$, and operational performance $\bar{r}=0.47\left(\bar{r}_{\mathrm{c}}=0.55\right)$.

$\mathrm{H} 3$ suggests that studies relying on the relationship learning perspective would report a stronger IOLperformance relationship than studies relying on another theoretical foundation. The analysis provides partial support for this hypothesis. The effect for studies drawing on relationship learning is 
Rajala, Anni (2018). Examining the effects of interorganizational learning on performance : a metaanalysis. Journal of business and industrial marketing, 33(4), 574-584.

$\bar{r}=0.48\left(\bar{r}_{\mathrm{c}}=0.55\right)$ compared to $\bar{r}=0.37\left(\bar{r}_{\mathrm{c}}=0.43\right)$ for studies that rely on another theoretical background of IOL. Studies relying on relationship performance can be treated as belonging to the same category, because their confidence intervals of these studies strongly overlaps. In contrast, in studies relying on another theoretical background the confidence intervals varied, as did the extent of the overlaps, which indicates that these studies cannot be treated as elements of the same population. Further, H3 was also tested without the samples from the Selnes and Sallis study (2003), and the results show that the effect of relationship learning on performance remains positive $(\bar{r}=0.43$; $\bar{r}_{\mathrm{c}}=0.49$ ), but somewhat weaker than those obtained with the Selnes and Sallis samples included.

$\mathrm{H} 4$ predicts that the IOL-performance connection is moderated by global diversity, and more specifically that IOL-performance connection is stronger in studies using samples from single countries than research designs relying on samples from multiple countries. The analysis did not provide support to $\mathrm{H} 4$, as the estimated effect size of samples from a single country is $\bar{r}=0.39$ $\left(\bar{r}_{\mathrm{c}}=0.45\right)$ while the effect size of samples from multiple countries is $\bar{r}=0.63\left(\bar{r}_{\mathrm{c}}=0.69\right)$, indicating that IOL-performance connection is stronger in studies using samples from multiple countries. However, the analysis revealed that global breadth is a moderator between IOL and performance, but in the opposite direction to that hypothesized.

H5 suggests that the IOL-performance relationship is moderated by industry diversity. The effect for studies using samples from a single industry is $\bar{r}=0.40\left(\bar{r}_{\mathrm{c}}=0.46\right)$ compared to $\bar{r}=0.46\left(\bar{r}_{\mathrm{c}}=0.55\right)$ for studies that used samples from multiple industries. Thus, H5 is not supported. Then again, the analysis indicates that industry diversity is a moderator between IOL and performance, but in the opposite direction to that hypothesized. Finally, H6 predicting that IOL-performance connection is stronger in studies using samples only from suppliers was not supported. The effects for studies using only supplier samples is $\bar{r}=0.44\left(\bar{r}_{\mathrm{c}}=0.50\right)$, while the effects for studies using customer samples and both 
Rajala, Anni (2018). Examining the effects of interorganizational learning on performance : a metaanalysis. Journal of business and industrial marketing, 33(4), 574-584.

customer and supplier samples are $\bar{r}=0.50\left(\bar{r}_{\mathrm{c}}=0.57\right)$ and $\bar{r}=0.58\left(\bar{r}_{\mathrm{c}}=0.65\right)$, respectively. The results of the analyses are presented in Table 2.

Please insert Table 2 about here

\section{Discussion}

This study makes an important contribution by discussing on the extent to which interorganizational learning impacts performance. More specifically, based on a sample of 4618 cases within 21 studies (26 samples), the results show that interorganizational learning is related to performance at $\bar{r}_{\mathrm{c}}=0.53$. This means that roughly $53 \%$ of the utility available from predicting performance difference among companies is provided by interorganizational learning. This does not mean that interorganizational learning itself is a lever for improving performance. However, the finding does indicate that significant benefits can flow from having higher levels of interorganizational learning than one's competitors.

One benefit of meta-analysis is its ability to clarify unresolved questions in an area of study (Lewin \& Donthu, 2005). Moreover, meta-analysis enables scholars to statistically aggregate findings across studies and through that aggregation derive more accurate estimations of the empirical evidence around a phenomenon (Wowak et al., 2013). This study complements the recently conducted metaanalysis by Wowak et al. (2013), on the effects of supply chain knowledge on performance. That work found that possessing supply chain knowledge is related to performance at $\bar{r}_{\mathrm{c}}=0.39$. Comparing the results to those of the current study, it can be concluded that interorganizational learning has an even stronger impact on performance than supply chain knowledge. This is not surprising, because 
Rajala, Anni (2018). Examining the effects of interorganizational learning on performance : a metaanalysis. Journal of business and industrial marketing, 33(4), 574-584.

supply chain knowledge is defined as "knowledge within a firm about its supply chain partners and processes" (Wowak et al., 2013, p. 844), while interorganizational learning is a complete process where information and knowledge is transferred, through which companies learn.

Moreover, the results show that the relationship between IOL and performance is moderated by different factors. More specifically, the results show that IOL has a stronger impact on relationship performance than other types of performance (i.e., market, operational, or innovation). The effects of IOL on relationship performance are intuitive whereas the other performance types take time to manifest, for example the effects on innovation performance may sometimes take years to manifest. Therefore, the results suggest that scholars need to incorporate a temporal lag when investigating market, innovation, or operational performance as companies often need to engage in IOL and then integrate what they learn in order to gain competitive advantages. If market, operational, or innovation performance are examined without a temporal lag, the results actually may not capture the true impact of IOL. Further, this also indicates that the effects sizes used in this meta-analysis may be quite conservative estimates. The results indicate that IOL has a weaker relationship with market performance than with other types of performance. These same results provide support for an assumption that market performance consists of a great number of influential factors, and thus it might be unproductive to explain differences in market performance by reference to IOL. This result therefore provides insight for scholars considering incorporating performance measures into their future IOL research.

This study extends the IOL literature by examining the moderating effects of global diversity, industry diversity, and source of data in the IOL-performance relationship. The results indicate that differences in findings in the literature may be attributed to the diversity of the research design. More specifically, the findings show that using samples from multiple countries, from multiple industries, 
Rajala, Anni (2018). Examining the effects of interorganizational learning on performance : a metaanalysis. Journal of business and industrial marketing, 33(4), 574-584.

and/or from both customers and suppliers results in a stronger IOL-performance relationship. However, the difference in the magnitude of the IOL-performance relationship was not substantial in different research settings, except that of global diversity. This indicates that the IOL-performance relationship seems to be a universal phenomenon that is not overly sensitive to differences in research settings, but also that the IOL-performance relationship is not a country-specific phenomenon. Thus, the study contributes to the IOL literature by providing further evidence that IOL is an important antecedent of performance.

Finally, the results show that studies relying on the relationship learning perspective reveal stronger IOL-performance relationships than studies drawing other theoretical background. Most of the quantitative studies found in the systematic review rely on the relationship learning view, which might be because it has well established measures that are easily adopted. Studies that used other theoretical backgrounds had varying conceptualizations and measures, which resulted in finding weaker IOLperformance relationships. The fact that the majority of the identified studies draw on the relationship learning perspective also indicates that scholars have favored the view of joint learning in relationships over that of interactive learning, which is essentially knowledge acquired from suppliers and applied for a firm to acquire private benefits. Moreover, this paper contributes to IOL literature by reviewing the different perspectives on IOL and making an effort to collate the concepts used and illustrate the different IOL perspectives.

\subsection{Managerial implications}

This study provides valuable knowledge for practitioners. The results suggest that practitioners should invest time in establishing and maintaining practices that enhance interorganizational learning in their close inter-firm relationships. First, practitioners should pay attention to their company's network 
Rajala, Anni (2018). Examining the effects of interorganizational learning on performance : a metaanalysis. Journal of business and industrial marketing, 33(4), 574-584.

capability, in other words, they should develop the ability to handle and exploit relationships (see Vesalainen \& Hakala, 2014). Network capability also includes the ability to interact with other organizations, and the ability to develop relationships (Vesalainen \& Hakala, 2014). More specifically, information sharing has been viewed as a basis of IOL, which means that practitioners should create structures that enable information sharing in their interorganizational relationships. Establishing information sharing norms requires time and resources (Tong \& Crosno, 2015), and in practice, information sharing is done by individuals known as boundary spanners working within the parameters set by an organization. Accordingly, enhancing IOL requires enabling structures but also clear rules on which information can be shared, and on how acquired information should be treated. However, information sharing per se does not deliver IOL, and it is important to recognize that an organization's capability to interpret and utilize the knowledge it acquires are central to its achieving competitive advantage.

Second, practitioners should be clear on the goal of each interorganizational relationship; whether that be short-term efficiency gains or longer-term learning-enhancing effects. Moreover, it has been argued that in short-term market relationships, learning occurs through observation, while in in longterm partnerships, companies learn jointly through continuous interaction (Kohtamäki \& Bourlakis, 2012). Thus, practitioners should assess their company's relationships and clearly define the type and desired interaction intensity of a relationship. Then the structures that enable information sharing, and further IOL, should be created or maintained in order to take advantage of the benefits. In addition, practitioners should be aware that if the other party is not willing to share information to a similar degree, the possibility of self-interest seeking increases, in other words, information asymmetry increases the risk of opportunism (Tong \& Crosno, 2015). 
Rajala, Anni (2018). Examining the effects of interorganizational learning on performance : a metaanalysis. Journal of business and industrial marketing, 33(4), 574-584.

5.2 Limitations and suggestions for future research

A comprehensive effort was undertaken to analyze the literature in order to deliver research findings capable of enriching the theory on the IOL-performance link. However, the results of the study should be considered in light of some limitations. First, relatively few published studies have investigated the IOL-performance link, meaning the meta-analysis could rely on only a relatively small number of studies (21 studies, 26 samples). Although that sample size is in line with other meta-analyses, further meta-analysis should be conducted when the number of studies increases. Second, the degree of artifact correction achieved through this meta-analysis is limited. This study covered sampling error and measurement error based on their availability in the studies included in the analysis, but inevitably the current research could not address other potential artifacts.

The study offers several suggestions for future research. The literature review conducted shows that there is a lack of consensus in defining IOL, thus, future research is needed to unify the concepts and activities that comprise IOL. Moreover, the findings of the study should encourage future research to use multinational and/or multi-industry data sets. This suggestion is in line with the argument of Cheung et al. (2010) that multi-country representation is not well understood in IOL studies.

Furthermore, the company interface is multifaceted, such that information sharing does not occur between companies, but between people, or boundary spanners. Therefore, the reality of a company interface is multiple boundary spanners interacting with the boundary spanners of another organization. However, most of the data in the studies included in the meta-analysis were collected using the key informant approach, and as such do not account for the multifaceted nature of company boundaries. Thus, future research should approach interorganizational learning from a multilevel perspective, and conduct multilevel analyses. A multilevel approach makes it possible to gather data, 
Rajala, Anni (2018). Examining the effects of interorganizational learning on performance : a metaanalysis. Journal of business and industrial marketing, 33(4), 574-584.

for example, from multiple respondents and from dyadic settings in one study. The approach could benefit IOL studies by delivering a more complete picture of how IOL is actually formed in relationships. Future research could, for example, study if a business network consisting of learning relationships performs better than a business network consisting of market relationships. Or if a company that targets having many learning relationships performs better than a company trusting in a few learning relationships. Moreover, multilevel studies could benefit the whole supply chain, and interorganizational relationship research streams. 
Rajala, Anni (2018). Examining the effects of interorganizational learning on performance : a metaanalysis. Journal of business and industrial marketing, 33(4), 574-584.

\section{References}

Chang, K.-H., \& Gotcher, D. F. (2007). Safeguarding investments and creation of transaction value in asymmetric international subcontracting relationships: The role of relationship learning and relational capital. Journal of World Business, 42(4), 477-488. http://doi.org/10.1016/j.jwb.2007.06.008

Chang, K.-H., \& Gotcher, D. F. (2010). Conflict-coordination learning in marketing channel relationships: The distributor view. Industrial Marketing Management, 39(2), 287-297. http://doi.org/10.1016/j.indmarman.2008.10.003

Chen, Y.-S., Lin, M.-J. J., \& Chang, C.-H. (2009). The positive effects of relationship learning and absorptive capacity on innovation performance and competitive advantage in industrial markets. Industrial Marketing Management, $\quad 38(2), \quad$ 152-158. http://doi.org/10.1016/j.indmarman.2008.12.003

Cheung, M.-S., Myers, M. B., \& Mentzer, J. T. (2010). Does relationship learning lead to relationship value? A cross-national supply chain investigation. Journal of Operations Management, 28(6), 472-487. http://doi.org/10.1016/j.jom.2010.01.003

Cheung, M.-S., Myers, M. B., \& Mentzer, J. T. (2011). The value of relational learning in global buyer-supplier exchanges: A dyadic perspective and test of the pie-sharing premise. Strategic Management Journal, 32(10), 1061-1082. http://doi.org/10.1002/smj

Cheung, M. W. L., \& Vijayakumar, R. (2016). A Guide to Conducting a Meta-Analysis. Neuropsychology Review, 26(2), 121-128. http://doi.org/10.1007/s11065-016-9319-z

Combs, J. G., \& Ketchen, D. J. (2003). Why do firms use franchising as an entrepreneurial strategy?: A meta-analysis. Journal of Management, 29(3), 443-465. http://doi.org/10.1016/S01492063(03)00019-9

Crook, T. R., Ketchen JR, D. J., Combs, J. G., \& Todd, S. Y. (2008). Strategic resources and performance: A meta-analysis. Strategic Management Journal, 29, 1141-1154. 
Rajala, Anni (2018). Examining the effects of interorganizational learning on performance : a metaanalysis. Journal of business and industrial marketing, 33(4), 574-584.

http://doi.org/10.1002/smj.703

Fang, S.-R., Fang, S.-C., Chou, C.-H., Yang, S.-M., \& Tsai, F.-S. (2011). Relationship learning and innovation: The role of relationship-specific memory. Industrial Marketing Management, 40(5), 743-753. http://doi.org/10.1016/j.indmarman.2011.02.005

Gao, Y., Li, Y., Cheng, M., \& Feng, G. (2017). How does market learning affect radical innovation? The moderation roles of horizontal ties and vertical ties. Journal of Business \& Industrial Marketing, 32(1), 57-74.

Hammervoll, T. (2012). Managing interaction for learning and value creation in exchange relationships. Journal of Business Research, 65(2), 128-136. http://doi.org/10.1016/j.jbusres.2011.05.011

Hernández-Espallardo, M., Rodríguez-Orejuela, A., \& Sánchez-Pérez, M. (2010). Interorganizational governance, learning and performance in supply chains. Supply Chain Management: An International Journal, 15(2), 101-114. http://doi.org/10.1108/13598541011028714

Huang, Y.-T., \& Chu, W. (2010). Enhancement of product development capabilities of OEM suppliers: inter- and intra-organisational learning. Journal of Business \& Industrial Marketing, 25(2), 147-158. http://doi.org/10.1108/08858621011017769

Huang, J., \& Li, Y. (2017). The mediating role of ambidextrous capability in learning orientation and new product performance. Journal of Business \& Industrial Marketing, 32(5), 613-624.

Hunter, J. E., \& Schmidt, F. L. (1994). Estimation of sampling error variance in the meta-analysis of correlations: Use of average correlation in the homogeneous case. Journal of Applied Psychology, 79(2), 171-177.

Håkansson, H., \& Shenota, I. (1995). Developing relationships in business networks. London: Routledge. http://doi.org/10.1016/j.indmarman.2004.12.007

Jean, R.-J. B., Chiou, J.-S., \& Sinkovics, R. R. (2016). Interpartner learning, dependence asymmetry 
Rajala, Anni (2018). Examining the effects of interorganizational learning on performance : a metaanalysis. Journal of business and industrial marketing, 33(4), 574-584.

and radical innovation in customer-supplier relationships. Journal of Business \& Industrial Marketing, 31(6), 732-742.

Jean, R.-J. B., Kim, D., \& Sinkovics, R. R. (2012). Drivers and Performance Outcomes of Supplier Innovation Generation in Customer-Supplier Relationships: The Role of Power-Dependence. Decision Sciences, 43(6), 1003-1038. http://doi.org/10.1111/j.1540-5915.2012.00380.x

Jean, R.-J. B., \& Sinkovics, R. R. (2010). Relationship learning and performance enhancement via advanced information technology: The case of Taiwanese dragon electronics firms. International Marketing Review, 27(2), 200-222. http://doi.org/10.1108/02651331011037520

Jean, R.-J. B., Sinkovics, R. R., \& Kim, D. (2010). Drivers and Performance Outcomes of Relationship Learning for Suppliers in Cross-Border Customer-Supplier Relationships: The Role of Communication Culture. Journal of International Marketing, 18(1), 63-85. http://doi.org/10.1509/jimk.18.1.63

Johnson, J. L., \& Sohi, R. S. (2003). The development of interfirm partnering competence: Platforms for learning, learning activities, and consequences of learning. Journal of Business Research, 56(9), 757-766. http://doi.org/10.1016/S0148-2963(01)00260-0

Knight, L. (2002). Network Learning: Exploring Learning by Interorganizational Networks. Human Relations, 55(4), 427-454. http://doi.org/10.1177/0018726702554003

Kohtamäki, M., \& Bourlakis, M. (2012). Antecedents of relationship learning in supplier partnerships from the perspective of an industrial customer: the direct effects model. Journal of Business \& Industrial Marketing, 27(4), 299-310. http://doi.org/10.1108/08858621211221670

Kohtamäki, M., \& Partanen, J. (2016). Co-creating value from knowledge-intensive business services in manufacturing firms: The moderating role of relationship learning in supplier-customer interactions. Journal of Business Research. http://doi.org/10.1016/j.jbusres.2016.02.019

Lane, P. J., \& Lubatkin, M. (1998). Relative absorptive capacity and interorganization learning. Strategic Management Journal, 19(5), 461-477. 
Rajala, Anni (2018). Examining the effects of interorganizational learning on performance : a metaanalysis. Journal of business and industrial marketing, 33(4), 574-584.

Lewin, J. E., \& Donthu, N. (2005). The influence of purchase situation on buying center structure and involvement: A select meta-analysis of organizational buying behavior research. Journal of Business Research, 58(10), 1381-1390. http://doi.org/10.1016/j.jbusres.2004.09.004

Ling-yee, L. (2006). Relationship learning at trade shows: Its antecedents and consequences. Industrial Marketing Management, $\quad$ 35(2), 166-177. http://doi.org/10.1016/j.indmarman.2005.03.006

Liu, C.-L. E. (2012). An investigation of relationship learning in cross-border buyer-supplier relationships: The role of trust. International Business Review, 21(3), 311-327. http://doi.org/10.1016/j.ibusrev.2011.05.005

MacKelprang, A. W., \& Nair, A. (2010). Relationship between just-in-time manufacturing practices and performance: A meta-analytic investigation. Journal of Operations Management, 28(4), 283-302. http://doi.org/10.1016/j.jom.2009.10.002

McDaniel, M. A., Rothstein, H. R., \& Whetzel, D. L. (2006). Publication bias: A case study of four test vendors. Personnel Psychology, 59(4), 927-953. http://doi.org/10.1111/j.17446570.2006.00059.x

Nair, A. (2006). Meta-analysis of the relationship between quality management practices and firm performance-implications for quality management theory development. Journal of Operations Management, 24(6), 948-975. http://doi.org/10.1016/j.jom.2005.11.005

Rebolledo, C., \& Nollet, J. (2011). Learning from suppliers in the aerospace industry. International Journal of Production Economics, 129(2), 328-337. http://doi.org/10.1016/j.ijpe.2010.11.008

Salas, E., DiazGranados, D., Klein, C., Burke, C. S., Stagl, K. C., Goodwin, G. F., \& Halpin, S. M. (2008). Does team training improve team performance? A meta-analysis. Human Factors, 50(6), 903-933. http://doi.org/10.1518/001872008X375009.

Schildt, H., Keil, T., \& Maula, M. (2012). The temporal effects of relative and firm-level absorptive capacity on interorganizational learning. Strategic Management Journal, 33(10), 1154-1173. 
Rajala, Anni (2018). Examining the effects of interorganizational learning on performance : a metaanalysis. Journal of business and industrial marketing, 33(4), 574-584.

http://doi.org/10.1002/smj

Schmidt, F. L. (1996). Statistical significance testing and cumulative knowledge in psychology: Implications for training of researchers. Psychological Methods, 1(2), 115-129.

Schmidt, F. L., \& Hunter, J. E. (2015). Methods of meta-analysis: Correcting error and bias in research findings (3rd editio). SAGE Publications.

Selnes, F., \& Sallis, J. (2003). Promoting relationship learning. Journal of Marketing, 67(3), 80-95. http://doi.org/10.1509/jmkg.67.3.80.18656

Tong, P. Y., \& Crosno, J. L. (2015). Are information asymmetry and sharing good, bad, or context dependent? A meta-analytic review. Industrial Marketing Management, 56, 167-180. http://doi.org/10.1016/j.indmarman.2015.11.004

Vesalainen, J., \& Hakala, H. (2014). Strategic capability architecture: The role of network capability. Industrial Marketing Management, $\quad$ 43(6), 938-950. http://doi.org/10.1016/j.indmarman.2014.05.008

Whitener, E. M. (1990). Confusion of confidence intervals and credibility intervals in meta-analysis. Journal of Applied Psychology, 75(3), 315-321. http://doi.org/10.1037/0021-9010.75.3.315

Wowak, K. D., Craighead, C. W., Ketchen, D. J., \& Hult, G. T. M. (2013). Supply chain knowledge and performance: A meta-analysis. Decision Sciences, 44(5), 843-875. http://doi.org/10.1111/deci.12039

Yang, C.-F., \& Lai, C.-S. (2012). Relationship learning from organizational knowledge stores. Journal of Business Research, 65(3), 421-428. http://doi.org/10.1016/j.jbusres.2011.10.001

Yang, Y. (2012). Bilateral inter-organizational learning in corporate venture capital activity: Governance characteristics, knowledge transfer, and performance. Management Research Review, 35(5), 352-378. http://doi.org/10.1108/0140917121122227 
Rajala, Anni (2018). Examining the effects of interorganizational learning on performance : a meta-analysis. Journal of business and industrial marketing, 33(4), 574-584.

Table 1. Summary of studies used for meta-analysis.

\begin{tabular}{|c|c|c|c|c|c|c|c|c|}
\hline Authors & $\begin{array}{c}\text { Year } \\
\text { published }\end{array}$ & Journal & Source of data & $\begin{array}{c}\text { Sample } \\
\text { size }\end{array}$ & $\begin{array}{l}\text { Performance } \\
\text { type }\end{array}$ & Global breadth & Industry diversity & $\begin{array}{l}\text { Theoretical } \\
\text { background }\end{array}$ \\
\hline Sobrero \& Roberts & 2001 & Management Science & Both & 50 & relationship & Multiple countries & & Other \\
\hline Johnson \& Sohi & 2003 & Journal of Business Research & & 176 & relationship & Single country & Single industry & Other \\
\hline \multirow{2}{*}{ Selnes \& Sallis } & \multirow{2}{*}{2003} & \multirow{2}{*}{ Journal of Marketing } & Customer & 315 & relationship & \multirow[t]{2}{*}{ Multiple countries } & & Relationship learning \\
\hline & & & Supplier & 315 & relationship & & & Relationship learning \\
\hline $\mathrm{Li}$ & 2006 & Industrial Marketing Management & & 414 & relationship & Single country & & Relationship learning \\
\hline Chang \& Gotcher & 2007 & Journal of World Business & Supplier & 118 & relationship & Single country & Single industry & Relationship learning \\
\hline Chang \& Gotcher & 2008 & $\begin{array}{l}\text { International Journal of Technology } \\
\text { Management }\end{array}$ & Supplier & 118 & relationship & Single country & Single industry & Relationship learning \\
\hline Chen et al. & 2009 & Industrial Marketing Management & & 106 & $\begin{array}{l}\text { market } \\
\text { innovation }\end{array}$ & Single country & Single industry & Relationship learning \\
\hline Chang \& Gotcher & 2010 & Industrial Marketing Management & Supplier & 101 & market & Single country & Single industry & Relationship learning \\
\hline Jean et al. & 2010 & Journal of International Marketing & Supplier & 246 & $\begin{array}{l}\text { market } \\
\text { innovation }\end{array}$ & Single country & Single industry & Relationship learning \\
\hline Jean \& Sinkovics & 2010 & International Marketing Review & & 246 & relationship & & & Relationship learning \\
\hline \multirow{2}{*}{ Cheung et al. } & \multirow{2}{*}{2010} & \multirow{2}{*}{ Journal of Operations Management } & Customer & 126 & operational & Multiple countries & Multiple industries & Relationship learning \\
\hline & & & Supplier & 126 & operational & & & \\
\hline $\begin{array}{l}\text { Hernandez-Espallardo et } \\
\text { al. }\end{array}$ & 2010 & $\begin{array}{l}\text { Supply Chain Management: An International } \\
\text { Journal }\end{array}$ & & 219 & operational & Single country & Single industry & Other \\
\hline Huang \& Chu & 2010 & Journal of Business and Industrial Marketing & Supplier & 147 & operational & Single country & Single industry & Other \\
\hline \multirow{2}{*}{ Cheung et al. } & \multirow{2}{*}{2011} & \multirow{2}{*}{ Strategic Management Journal } & Customer & 126 & relationship & Multiple countries & Multiple industries & Relationship learning \\
\hline & & & Supplier & 126 & relationship & & & \\
\hline Zhao \& Wang & 2011 & Journal of Strategic Marketing & Both & 306 & relationship & Single country & Single industry & Relationship learning \\
\hline Fang et al. & 2011 & Industrial Marketing Management & & 161 & innovation & Single country & Single industry & Relationship learning \\
\hline Liu & 2012 & International Business Review & & 160 & relationship & Single country & Single industry & Relationship learning \\
\hline Leal-Rodriguez et al. & 2013 & Service Industries Journal & & 139 & innovation & Single country & Single industry & Relationship learning \\
\hline Leal-Rodriguez et al. & 2014 & International Journal of Project Management & & 110 & innovation & Single country & Single industry & Relationship learning \\
\hline Wang \& Hsu & 2014 & Technological Forecasting and Social Change & Both & 104 & innovation & Single country & Single industry & Relationship learning \\
\hline Liu & 2015 & Management Learning & & 211 & operational & Single country & Multiple industries & Other \\
\hline
\end{tabular}


Rajala, Anni (2018). Examining the effects of interorganizational learning on performance : a meta-analysis. Journal of business and industrial marketing, 33(4), 574-584.

Table 2. Meta-analytic results.

\begin{tabular}{|c|c|c|c|c|c|c|c|c|c|c|}
\hline Hypothesis & $\mathrm{N}$ & $\mathrm{K}$ & $\mathrm{r}^{-}$ & $\overline{r_{c}}$ & $\sigma_{r^{-}}^{2}$ & $\sigma_{\mathrm{e}}^{2}$ & $\begin{array}{l}\text { Residual } \\
\text { variance }\end{array}$ & $99 \% \mathrm{CI}$ & $95 \% \mathrm{CI}$ & $90 \% \mathrm{CI}$ \\
\hline H1: IOL - Performance & 4618 & 25 & 0.46 & 0.53 & 0.03 & 0.00 & 0.02 & $0,38: 0,55$ & $0,40: 0,53$ & $0,41: 0,52$ \\
\hline \multicolumn{11}{|l|}{ H2: Performance type } \\
\hline Market performance & 453 & 3 & 0.36 & 0.43 & 0.00 & 0.01 & 0.00 & $0,26: 0,46$ & $0,28: 0,44$ & $0,30: 0,42$ \\
\hline Relationship performance & 2470 & 12 & 0.50 & 0.57 & 0.03 & 0.00 & 0.03 & $0,38: 0,63$ & $0,41: 0,60$ & $0,42: 0,59$ \\
\hline Innovation performance & 866 & 6 & 0.40 & 0.44 & 0.03 & 0.00 & 0.02 & $0,22: 0,57$ & $0,26: 0,53$ & $0,28: 0,51$ \\
\hline $\begin{array}{l}\text { Operational performance } \\
\text { H3: Theoretical } \\
\text { background }\end{array}$ & 829 & 5 & 0.47 & 0.55 & 0.02 & 0.00 & 0.02 & $0,29: 0,64$ & $0,34: 0,60$ & $0,36: 0,58$ \\
\hline Relationship learning & 3815 & 21 & 0.48 & 0.55 & 0.02 & 0.00 & 0.02 & $0,38: 0,57$ & $0,41: 0,55$ & $0,43: 0,54$ \\
\hline Other & 803 & 5 & 0.37 & 0.43 & 0.03 & 0.00 & 0.03 & $0,16: 0,58$ & $0,21: 0,53$ & $0,23: 0,51$ \\
\hline \multicolumn{11}{|l|}{ H4: Global diversity } \\
\hline Single country & 2942 & 17 & 0.39 & 0.45 & 0.02 & 0.00 & 0.01 & $0,31: 0,48$ & $0,33: 0,46$ & $0,34: 0,45$ \\
\hline Multiple countries & 1184 & 7 & 0.63 & 0.69 & 0.03 & 0.00 & 0.02 & $0,47: 0,79$ & $0,51: 0,75$ & $0,53: 0,73$ \\
\hline \multicolumn{11}{|l|}{ H5: Industry diversity } \\
\hline Single industry & 2317 & 15 & 0.40 & 0.46 & 0.02 & 0.00 & 0.02 & $0,31: 0,50$ & $0,33: 0,48$ & $0,34: 0,47$ \\
\hline Multiple industries & 715 & 5 & 0.46 & 0.55 & 0.01 & 0.00 & 0.01 & $0,33: 0,59$ & $0,36: 0,56$ & $0,38: 0,54$ \\
\hline \multicolumn{11}{|l|}{ H6: Source of data } \\
\hline Both & 1090 & 5 & 0.58 & 0.65 & 0.05 & 0.00 & 0.05 & $0,32: 0,84$ & $0,38: 078$ & $0,41: 0,75$ \\
\hline Customer & 378 & 3 & 0.50 & 0.57 & 0.00 & 0.00 & 0.00 & $0,44: 0,56$ & $0,45: 0,55$ & $0,46: 0,54$ \\
\hline Supplier & 1016 & 7 & 0.44 & 0.50 & 0.01 & 0.00 & 0.00 & $0,35: 0,53$ & $0,37: 0,51$ & $0,38: 0,50$ \\
\hline
\end{tabular}


Rajala, Anni (2018). Examining the effects of interorganizational learning on performance : a meta-analysis. Journal of business and industrial marketing, 33(4), 574-584. 